\title{
Constrained? An Analysis of U.S. Academic Library Shifts in Spending, Staffing, and Utilization, 1998-2008
}

\author{
John J. Regazzi
}

The study provides an analysis of U.S. academic library spending, staffing and utilization trends from data collected during the period between 1998 and 2008. Data used in this study are part of the NCES biennial survey of approximately 3,700 degree-granting postsecondary institutions. Confirming previous studies, there has been an order of magnitude change in the expenditure of e-books and e-serials; but, contrary to the view of being fiscally restrained, libraries have received investments and increases of approximately 12 percent above inflation over the period with significant increases in nearly every area of library operation. Library staffing is being diversified, while use of physical library assets are in decline for every metric in the study - gate count, reference service, general and reserve circulation. Academic libraries cannot be treated as a homogenous group of institutions, and the study analyzes shifts by type, size, and Carnegie class of institution, illustrating significant difference among these classes of academic libraries, particularly among large doctoral institutions and other academic libraries, with large public and doctoral private institutions driving growth, while small and medium-sized academic libraries have fallen behind in both collections and staff investments.



or decades, at professional meetings and in the professional literature, librarians have voiced the view that academic library budgets are being eroded and constrained. These concerns were voiced nearly 30 years ago with the "serials crisis" and the effects that high journal prices were having on the overall fiscal capabilities of academic libraries. Uncertainty in the general economic conditions in the United States, starting a decade ago with the "dot com bust" and as recently as the 2008 recession and recent deficit legislation, has raised more concern regarding the financial viability of academic libraries to meet the growing and changing information demands of students and faculty. This study attempts to provide, however, an evidence-based analysis of U.S. academic library fiscal and funding trends from 1998 to 2008 only, using publicly available research.

John J. Regazzi is Professor in the Palmer School of Library E Information Science and Department of Computer Science and Management Engineering at Long Island University; e-mail: john.regazzi@liu. edu. (C) 2012 John J. Regazzi 
The study provides an analysis of U.S. academic library spending, staffing, and utilization trends from data collected during the period between 1998 and 2008 from the National Center for Education Statistics (NCES). The study seeks to explore and analyze three issues:

1. What characterizes the shift in overall academic library spending on collections and staffing between 1998 and 2008 and what are the trends that exist according to institutional type (public, private/nonprofit, and private/for-profit), Carnegie classification, ${ }^{1}$ and size of institution based on student enrollments;

2. What are the shifts in the use of the physical library assets between 1998 and 2008; and

3. Which subsets of institutions, if any, are driving the key changes in library spending, staffing, and utilization?

\section{Background}

Over the last decade, the role that academic libraries played as a repository of knowledge has come under tremendous economic and technological challenges. A number of studies have identified several key catalysts for these challenges. No longer are academic libraries focused on their traditional mission of being a supporting institution to other academic units. Rather, they are undergoing a transformation to adapt to the changing university campus landscape and, in certain situations, aiming to become the center of scholarly communications. ${ }^{2}$

In the last decade, the U.S. economy underwent two major financial crises, the dot com bust and the subprime housing market collapse with a period of significant growth between these-a boom and bust cycle rarely seen in the U.S. economy. These major financial events triggered funding pressures across the globe, resulting in academic libraries facing an intensified period of financial cutbacks. ${ }^{3}$ At the same time, the rapidly evolving digital information landscape is forcing academic libraries to adapt from being just a print repository of knowledge to providing a much more diverse set of electronic resources and services, necessitating increased investments that can provide the required higher level of service, but exacerbating funding pressures in this process of transformation. Although most academic libraries receive the majority of their funding from their parent institution and not directly from the government or through private grants, they are nevertheless affected by reductions in private philanthropy and government spending, as their parent institution received their funding from these services, as well as tuition and fees also affected by general economic and market conditions. ${ }^{4}$

In a landmark study, the Association of College and Research Libraries (ACRL) compiled a list of top trends that are affecting academic libraries. ${ }^{5}$ Of the top trends, ACRL noted: 1) budget constraints are significant and will affect the development of academic libraries; 2) clientele demands have dictated collection growth toward digital libraries; 3) changes in staffs' skill sets are needed and expanding; and 4) the need to justify the value that academic libraries provide their clientele is increasing steadily. ${ }^{6}$

Previous studies have looked at these trends from various perspectives. A study conducted by the Lumina Foundation for Education found that academic libraries in the United States are seeing a decline in spending at the end of this past decade from historic highs as a direct result of cutbacks in federal government funding and private sector donations due to the slowdown in the U.S. economy in 2007 and 2008. ${ }^{7}$ The prohibitive cost of maintaining a comprehensive collection of research materials particularly for electronic journals with significant price increases over this period of limited budgets and increasing user demands have been equally well documented in this and other studies.

Academic libraries' move toward digitalization of their collections will result in additional demands and strain on 
whatever limited financial resources these libraries have. ${ }^{8}$ Although there had been increased overall spending on academic support from 1998 to 2008 , according to one study, ${ }^{9}$ such increases are negligible and do not compensate for the rate of inflation over this time period.

The changes to digital libraries and user access to electronic information services have resulted in a change of skills required from libraries and librarians. There is now a need for library staffs to have a diversity of skills in technology enabled information access and management systems. The shift from print media to digital services is forcing many academic libraries to reassess the job descriptions and qualifications needed in the contemporary academic library. These new staffing requirements will place additional burdens on an already shrinking funding pool in academic libraries..$^{10}$ Others have noted a number of contributors to these trends including: growth in academic library positions not requiring master's degrees in Library Science (MLS); a migration of librarian responsibilities to support staff; increasing use of information technology requiring staff with commensurate skills; and addressing budget shortfalls through deprofessionalization rather than reducing collections. ${ }^{11}$

With the increased competition for limited financial resources, academic libraries are now facing a need to justify their core existence to their parent institution as well as their clientele. As a result, academic libraries are being pressured to demonstrate the value that they can impart to a student learning outcome. To assist academic libraries in documenting the value of the services they provide, there are several studies into this area, the most notable of which is the ACRL's research project called "Value, Outcomes and Return on Investment of Academic Libraries." 12 These efforts attempt to document the value of the use of the library for academic faculty, students, and staff in support of their work in the university environment. Since academic libraries are already repository of knowledge, some have seen these accountability demands as an opportunity to capitalize on the effective exploitation of expanded knowledge management initiatives. ${ }^{13}$

Some view these challenges as a mixture of threats and opportunities. Many have argued that academic libraries are currently going through a challenging time and many are facing significant financial constraints. This study will look at the overall reported financial, staffing, and utilization trends of academic libraries and analyze how different types of academic libraries may face these challenges differently.

\section{Methodology}

Data used in this study is part of the NCES biennial survey of approximately 3,700 U.S. degree-granting postsecondary institutions to provide an overview of academic libraries nationwide. The data analyzed for this study comes specifically from the NCES Library Statistics Program. NCES makes available data files for public use for each year in which the survey is conducted. For the purposes of this study, 1998, 2004, and 2008 data were used. The reason for the use of these years is based, in part, on the growth of electronic holdings by libraries after 1998. Indeed, in the documentation that accompanies the data collected during 1998, the NCES notes:

\section{In 1998, a substantial number of additional changes were made [to the survey], especially in the col- lections and expenditures sections. These changes reflect the extensive changes in library services that have occurred with regard to the devel- opment of electronic media.}

\section{Data Limitations}

As is the case with any data set populated by survey responses, there are some inherent limitations that should be recognized and understood before interpreting the results. These limitations 
can be organized into two areas: those due to methodology and those due to definitional constraints.

Methodological limitations include the following three: 1) due to the fact that not every institution responds to the survey, there is the possibility that differences in institution characteristics between responders and nonresponders might distort the results. The percentage of responding libraries has declined between 1998 and 2008, though even the lowest response rate of 86.7 percent in 2008 is very high relative to similar survey efforts, and it is unlikely that statistical outcomes are impacted in any substantive sense; 2 ) in some cases where institutions responded to the survey but did not provide information to individual items, data have been imputed based upon an established methodology developed by the NCES; ${ }^{14} 3$ ) general methodological limitations inherent in any survey research effort, based on sampling errors (noted in the first bullet) and nonsampling errors, meaning errors made by respondents or in the editing of data by the NCES.

Definitional limitations impact the ability to analyze collections information related to electronic holdings, in particular serial subscriptions. This is due to the fact that respondents are instructed to count titles twice if they are delivered in both paper and electronic format. This results in two main limitations since 1) respondents were instructed to report separate counts for paper and electronic serials in 1998, making comparisons between paper and electronic holdings with future years impossible; and 2) this eliminates the possibility of developing per-unit costs for electronic serial holdings. This limitation also impacts the ability to analyze expenditures for librarians and other professionals separately, since these reported expenditures are aggregated for librarians/other professionals and not tracked separately.

\section{Findings}

Shifts in Library Expenditures, 1998-2008

This section provides estimates of library expenditures for the period 1998-2008 as well as indications on whether any of these changes are significant. For the purposes of this report, significance testing is based on the results of evaluations between either totals or means for one group and confidence intervals for a comparison group. ${ }^{15}$ Throughout this report,

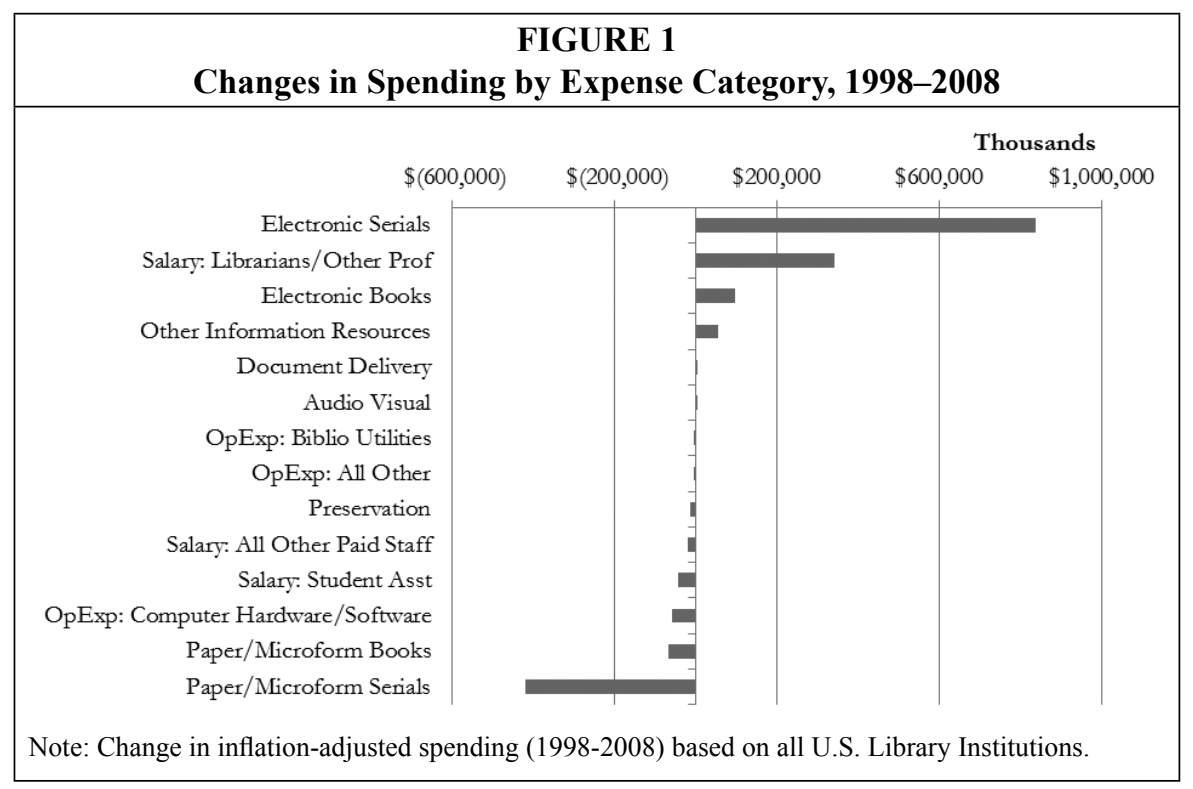


U.S. Academic Library Shifts in Spending, Staffing, and Utilization 453

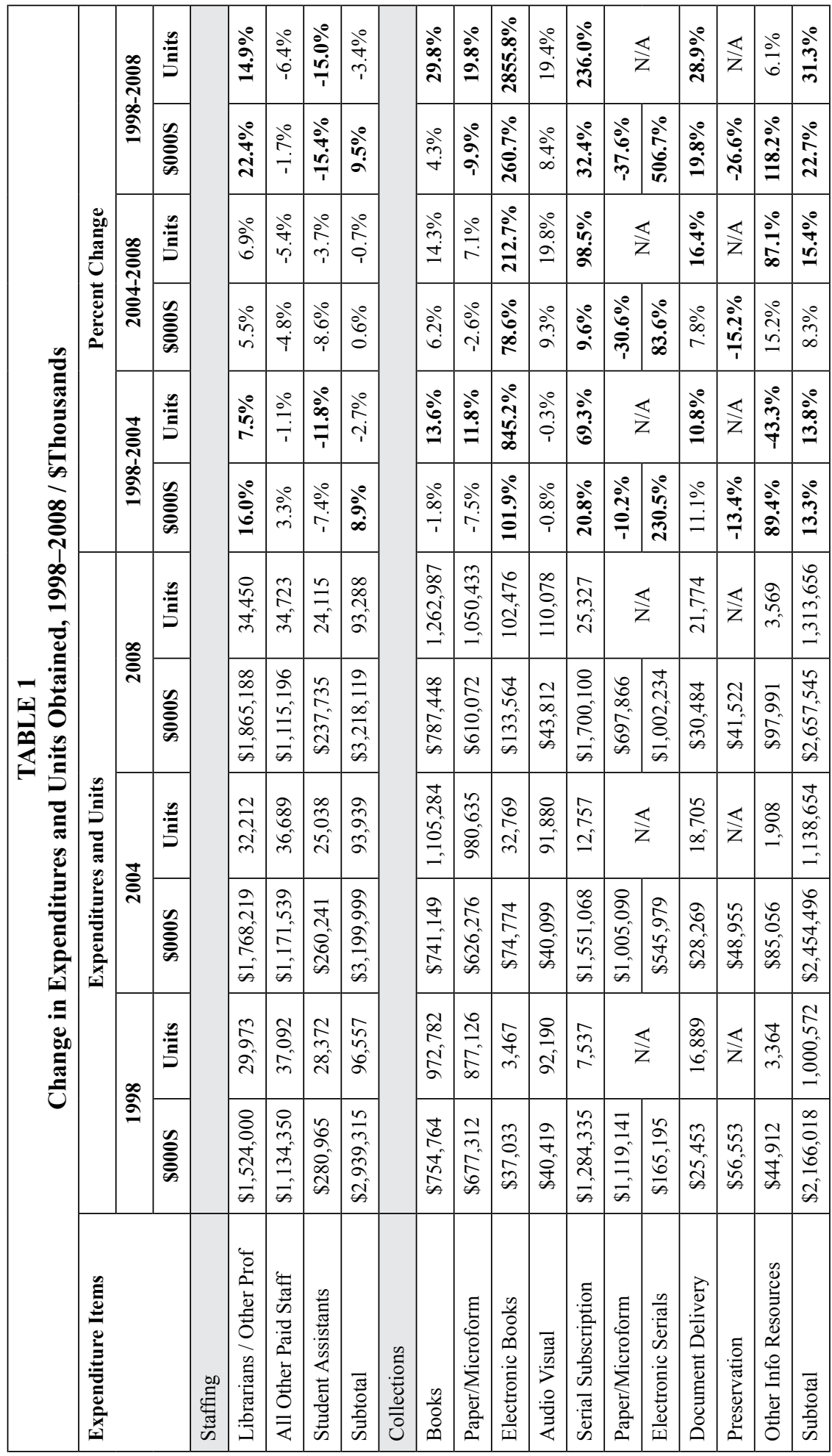




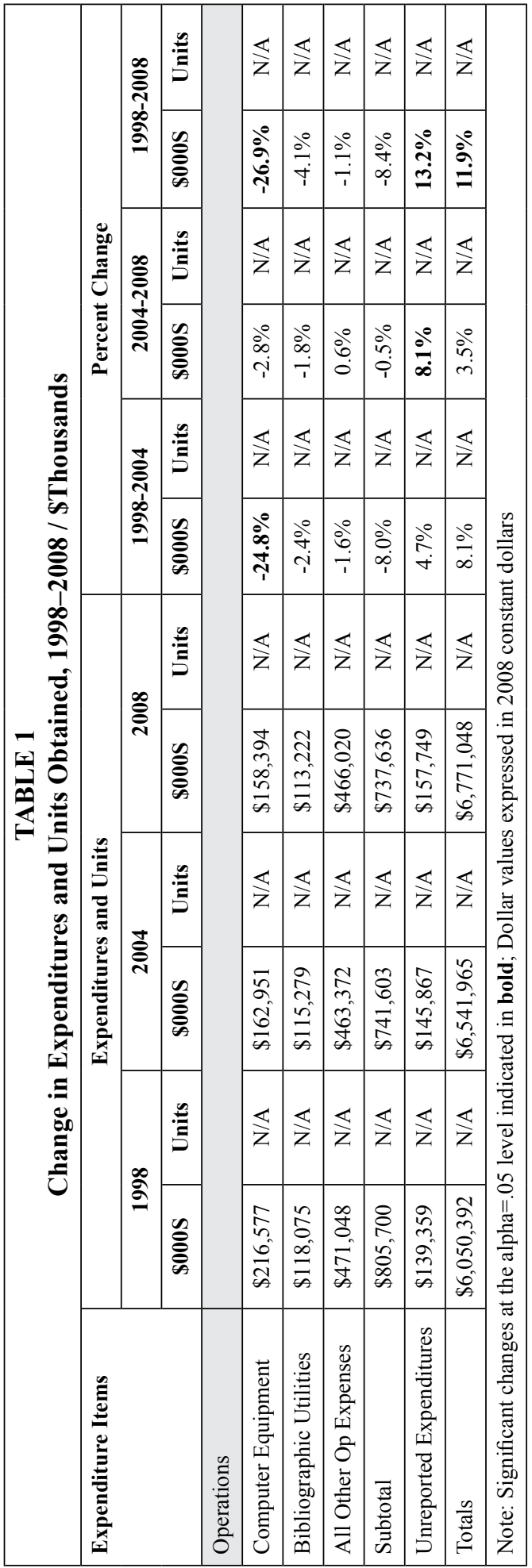

an alpha level of .05 was used to determine confidence intervals used in evaluating significance.

Figure 1 indicates changes in inflation-adjusted spending in $\$ 000$ from 1998 to 2008 for all libraries in the study for each major expense category.

Table 1 provides expenditure estimates for all institutions for the years 1998 and 2008, as well as indications of significant differences for each of the periods. As figure 1 and table 1 both indicate, there has been an order of magnitude change in the expenditure of electronic books and serials over the time period 1998-2008, a near 4-fold increase and 7-fold increase, respectively. Beyond e-materials and contrary to the view of the fiscally restrained, libraries have received investments and increases of approximately 12 percent above inflation over the period with significant increases in nearly every area of library operation, including 10 percent and 23 percent inflationadjusted growth for staffing and collection development respectively.

Type of Institution. In addition to prominent shifts in the use of e-materials, there are a number of other areas that have seen significant increases (or decreases) and indicate the underlying sea changes taking place in our nation's academic libraries. Table 2 provides a more in-depth view of these changes by viewing them according to institution type, a category that includes public sector institutions, private sector institutions (not-for-profit), and private sector institutions (for-profit). In terms of the increase in the number of institutions, the private/for-profit entities have experienced the greatest increase over the time period from 1998 to 2008 . In 1998, there were 457 institutions classified in the survey as private, for-profit, representing 
roughly 12 percent of all institutions. In 2008, 1 in 5 institutions are now classified as private, for-profit institutions, a more than 60 percent increase in the tenyear period. Public sector and private/ nonprofit institutions, by contrast, have declined over that same period.

There are some general observations that can be made upon an examination of table 2, as follows:

- There are significant changes across all institutions regardless of type (in some cases, these changes are declines in spending); however, increases in spending on electronic books, serial subscriptions, electronic serials, and other information resources show significant increases, regardless of institution type;

- In terms of total volume of spending, public and private/nonprofit institutions maintain the vast majority of spending, making up 98 percent across all three types; nevertheless, in

\begin{tabular}{|c|c|c|c|c|c|c|}
\hline \multicolumn{7}{|c|}{$\begin{array}{c}\text { TABLE } 2 \\
\text { Change in Expenditures, 1998-2008 (by Institution Type) / \$Thousands }\end{array}$} \\
\hline \multirow[t]{2}{*}{ ITEM } & 1998 & 2008 & 1998 & 2008 & 1998 & 2008 \\
\hline & \multicolumn{2}{|c|}{ Public } & \multicolumn{2}{|c|}{ Private Non-Profit } & \multicolumn{2}{|c|}{ Private For-Profit } \\
\hline Sample Size (Institutions) & 1578 & 1571 & 1618 & 1515 & 457 & 742 \\
\hline \multicolumn{7}{|l|}{ Staffing } \\
\hline Librarians / Other Prof & $\$ 939,494$ & $\$ 1,123,028$ & $\$ 577,137$ & $\$ 722,135$ & $\$ 7,370$ & $\$ 20,024$ \\
\hline All Other Paid Staff & $\$ 754,428$ & $\$ 733,993$ & $\$ 377,680$ & $\$ 374,000$ & $\$ 2,243$ & $\$ 7,204$ \\
\hline Student Assistants & $\$ 176,031$ & $\$ 139,599$ & $\$ 102,478$ & $\$ 93,667$ & $\$ 2,456$ & $\$ 4,469$ \\
\hline Subtotal & $\$ 1,869,953$ & $\$ 1,996,620$ & $\$ 1,057,294$ & $\$ 1,189,802$ & $\$ 12,068$ & $\$ 31,697$ \\
\hline \multicolumn{7}{|l|}{ Collections } \\
\hline Books & $\$ 422,122$ & $\$ 425,813$ & $\$ 323,803$ & $\$ 347,181$ & $\$ 8,840$ & $\$ 14,454$ \\
\hline Paper/Microform & $\$ 378,692$ & $\$ 326,624$ & $\$ 291,377$ & $\$ 273,047$ & $\$ 7,243$ & $\$ 10,401$ \\
\hline Electronic Books & $\$ 17,450$ & $\$ 74,126$ & $\$ 18,854$ & $\$ 56,986$ & $\$ 729$ & $\$ 2,452$ \\
\hline Audio Visual & $\$ 25,980$ & $\$ 25,062$ & $\$ 13,571$ & $\$ 17,149$ & $\$ 868$ & $\$ 1,601$ \\
\hline Serial Subscription & $\$ 781,490$ & $\$ 1,013,699$ & $\$ 497,141$ & $\$ 669,574$ & $\$ 5,704$ & $\$ 16,827$ \\
\hline Paper/Microform & $\$ 686,868$ & $\$ 387,416$ & $\$ 428,755$ & $\$ 305,096$ & $\$ 3,518$ & $\$ 5,353$ \\
\hline Electronic Serials & $\$ 94,622$ & $\$ 626,283$ & $\$ 68,387$ & $\$ 364,478$ & $\$ 2,186$ & $\$ 11,474$ \\
\hline Document Delivery & $\$ 16,176$ & $\$ 18,718$ & $\$ 9,183$ & $\$ 10,768$ & $\$ 94$ & $\$ 997$ \\
\hline Preservation & $\$ 32,453$ & $\$ 23,238$ & $\$ 23,972$ & $\$ 18,207$ & $\$ 128$ & $\$ 76$ \\
\hline Other Info Resources & $\$ 21,457$ & $\$ 50,434$ & $\$ 22,929$ & $\$ 46,975$ & $\$ 525$ & $\$ 582$ \\
\hline Subtotal & $\$ 1,273,698$ & $\$ 1,531,903$ & $\$ 877,028$ & $\$ 1,092,705$ & $\$ 15,291$ & $\$ 32,937$ \\
\hline \multicolumn{7}{|l|}{ Operations } \\
\hline Computer Equipment & $\$ 130,916$ & $\$ 99,934$ & $\$ 81,188$ & $\$ 56,129$ & $\$ 4,472$ & $\$ 2,330$ \\
\hline Bibliographic Utilities & $\$ 61,878$ & $\$ 64,756$ & $\$ 55,531$ & $\$ 47,422$ & $\$ 667$ & $\$ 1,044$ \\
\hline All Other Op Expenses & $\$ 261,640$ & $\$ 254,855$ & $\$ 206,041$ & $\$ 209,396$ & $\$ 3,367$ & $\$ 1,769$ \\
\hline Subtotal & $\$ 454,434$ & $\$ 419,545$ & $\$ 342,760$ & $\$ 312,948$ & $\$ 8,506$ & $\$ 5,143$ \\
\hline Unreported Expenditures & $\$ 59,736$ & $\$ 68,534$ & $\$ 60,874$ & $\$ 56,680$ & $\$ 18,750$ & $\$ 32,535$ \\
\hline Totals & $\$ 3,657,820$ & $\$ 4,016,601$ & $\$ 2,337,956$ & $\$ 2,652,136$ & $\$ 54,615$ & $\$ 102,311$ \\
\hline
\end{tabular}


terms of percentage changes, private/ for-profit institutions have nearly doubled total expenditures on an inflation-adjusted basis, reflecting of course the smaller base in 1998 and the explosive unit growth in institutions over the period;

- The increase in spending on electronic materials has occurred at the same time that there have been significant declines in spending on computer hardware and software. This is likely due to the shift in usage from library-centered applications to the availability of library materials via the Internet; as this trend has increased, the use of library-centered equipment has declined.

- Mass digitization of materials coupled with increasing use of digital access has led to the declining relative value of print materials held by libraries. This shift is likely to become of even greater importance when taking into account the cost of print material or storage costs. While the level of spending on electronic books is still low relative to paper expenditures, the ratio between spending on paper and e-book purchases has declined from 18 to 5 (adjusted for inflation) between 1998 and 2008 .

- In terms of items in which there has been a decline (in some instances, significant), Preservation and Computer Hardware/Software have seen the largest declines across all three types.

Carnegie Classification. Table 3 provides estimates of changes in expenditures according to the Carnegie classification categories that contain the largest number of institutions: entities that grant doctoral, master's, baccalaureate, and associate degrees, as well as all other institutions. For the purposes of this draft, this analysis includes all three institution types: public, private/nonprofit, and private/for-profit.

As is apparent in the tables presented to this point, significant changes are found across all institution types accord- ing to our collapsed Carnegie typology. In particular, electronic books, serial subscriptions, and electronic serials have seen significant increases in expenditures on an inflation-adjusted basis. Interestingly, traditional books have seen significant declines among both master and baccalaureate degree-granting entities, in direct contrast to doctoral institutions, which have also experienced a significant increase in inflation-adjusted expenditures for printed books between 1998 and 2008.

Size of Institution. An additional manner by which to view differences in spending is to segment institutions according to size. This is based on the enrollment data as provided through the IPEDS $^{16}$ public use data files. Segments according to size are based on information provided by the Carnegie Foundation and how they define classification segments. In the case of both type of institution and Carnegie classification, our size categories are closely matched to differences between those two variables, as table 4 below indicates. This similarity exists for both 1998 and 2008 data.

Table 5 provides information on changes in expenditures by size class. The size class of each institution is based solely on the level of enrollment at each institution. The categories indicating size class (<1,000; 1,000-2,999;3,000-9,999; and $10,000+)$ are based on those used by the Carnegie Foundation in classifying fouryear institutions.

As noted in previous tables, table 5 indicates further significant changes in the other areas. The increase in expenditures (inflation-adjusted) for electronic books, electronic serials, and other information resources has been significant regardless of size class designation. However, Preservation has seen significant declines across all size class categories, with the largest decline in the size class category 3,000-9,999, generally associated with public institutions.

Figure 2 plots all these institutional variables, type (with private/nonprofit and private/for-profit grouped together), 
U.S. Academic Library Shifts in Spending, Staffing, and Utilization 457






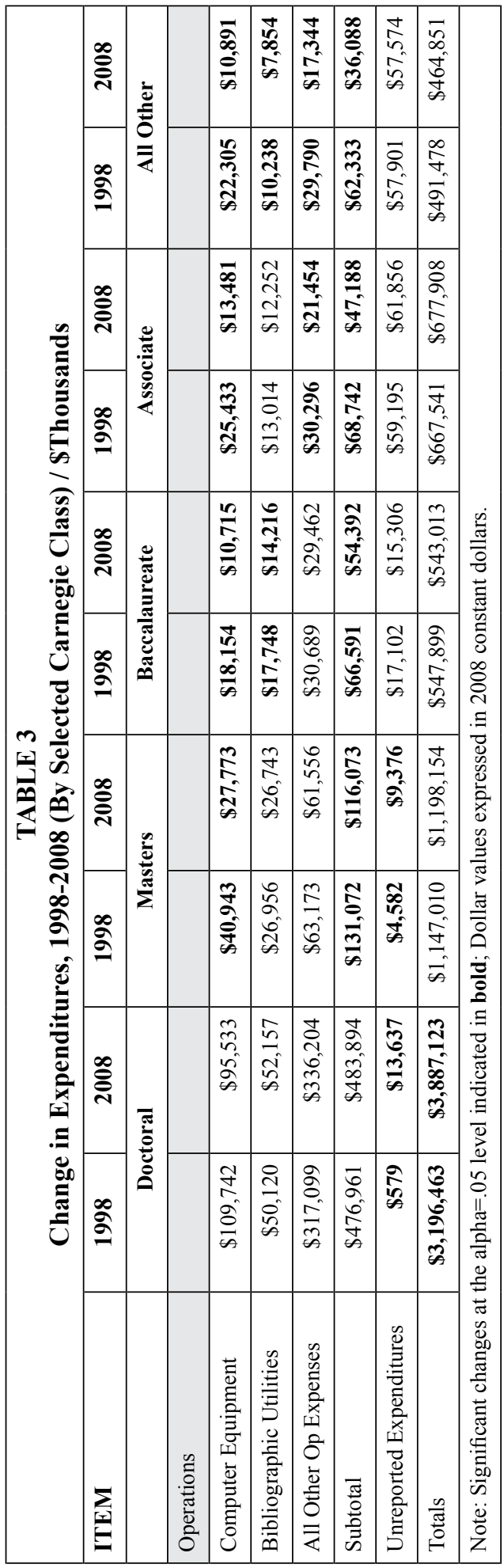

Carnegie classification, and size on two dimensions: staff expenditure and collection expenditures. Depending upon how much libraries increased or decreased their spending for staff and collections, four quadrants of library development over the period were constructed: expanding staff (those with increased staff expenditure and decreased collections expenditures), expanding collections (increased collections expenditures and decreased staffing expenditures), balanced leading (increased expenditures in both staffing and collections) and balanced lagging (decreased expenditures for both staffing and collections expenditures). The size of the bubble represents the total expenditure for that category of library. Additional axes were also created using the average increased spend for staffing $(9.5 \%)$ and collections (22\%) across the entire population. For example, in figure 2 the bubbles in the upper right corner of the graph illustrate that large and doctoral institutional libraries have increased their collections and staff spending well above the mean for all libraries during the period, while the bubbles in the lower left corner of the graph demonstrate that small and very small libraries have lagged the group in both staffing and collection development.

What is clear from this graph is that the large, doctoral, private universities are driving and leading the investments in academic libraries, with inflation-adjusted increases of 13 percent for staff and 25 percent for collections. Many other libraries, particularly small to medium-sized public and community college libraries, are not able to keep up with this pace of investment. Small and medium-sized libraries are lagging far behind, with decreases in both staff and collections expenditures and total expenditure. Though com- 


\begin{tabular}{|c|c|c|c|c|c|c|}
\hline \multicolumn{7}{|c|}{$\begin{array}{c}\text { TABLE } 4 \\
\text { Relation of Size Class to Type and Carnegie Class }\end{array}$} \\
\hline \multirow{2}{*}{$\begin{array}{l}\text { Size Class } \\
\text { (Enrolled) }\end{array}$} & \multicolumn{3}{|c|}{ Institution Type } & \multicolumn{3}{|c|}{ Selected Carnegie Classification } \\
\hline & Public & $\begin{array}{c}\text { Private } \\
\text { Non-Profit }\end{array}$ & $\begin{array}{c}\text { Private } \\
\text { For-Profit }\end{array}$ & Doctoral & Masters & Baccalaureate \\
\hline$<1,000$ & & $\boldsymbol{\theta}$ & $\boldsymbol{\theta}$ & & & $\boldsymbol{\theta}$ \\
\hline $1,000-2,999$ & & $\boldsymbol{\theta}$ & & & & $\boldsymbol{\theta}$ \\
\hline $3,000-9,999$ & $\boldsymbol{\theta}$ & & & & $\theta$ & \\
\hline $10,000+$ & $\theta$ & & & $\theta$ & & \\
\hline
\end{tabular}

munity college libraries have decreased their investments in collections, they have increased their staffing expenses over the period.

\section{Shifts in Staffing, 1998-2008}

This section explores shifts in the use of librarians and other professional staff between the years 1998 and 2008 across institution classes as explored in the previous section. Across all institutions, while changes in the staffing level of librarians has increased slightly $(9 \%)$, the use of other professional staff has increased at a much more significant rate ( $51 \%$ in the time period under study). The use of all other paid staff (except student assistants) has declined by 6 percent, and student assistant staffing has declined by 15 percent. Table 6 provides this information according to Carnegie classification. Analysis is based on mean staff FTEs per

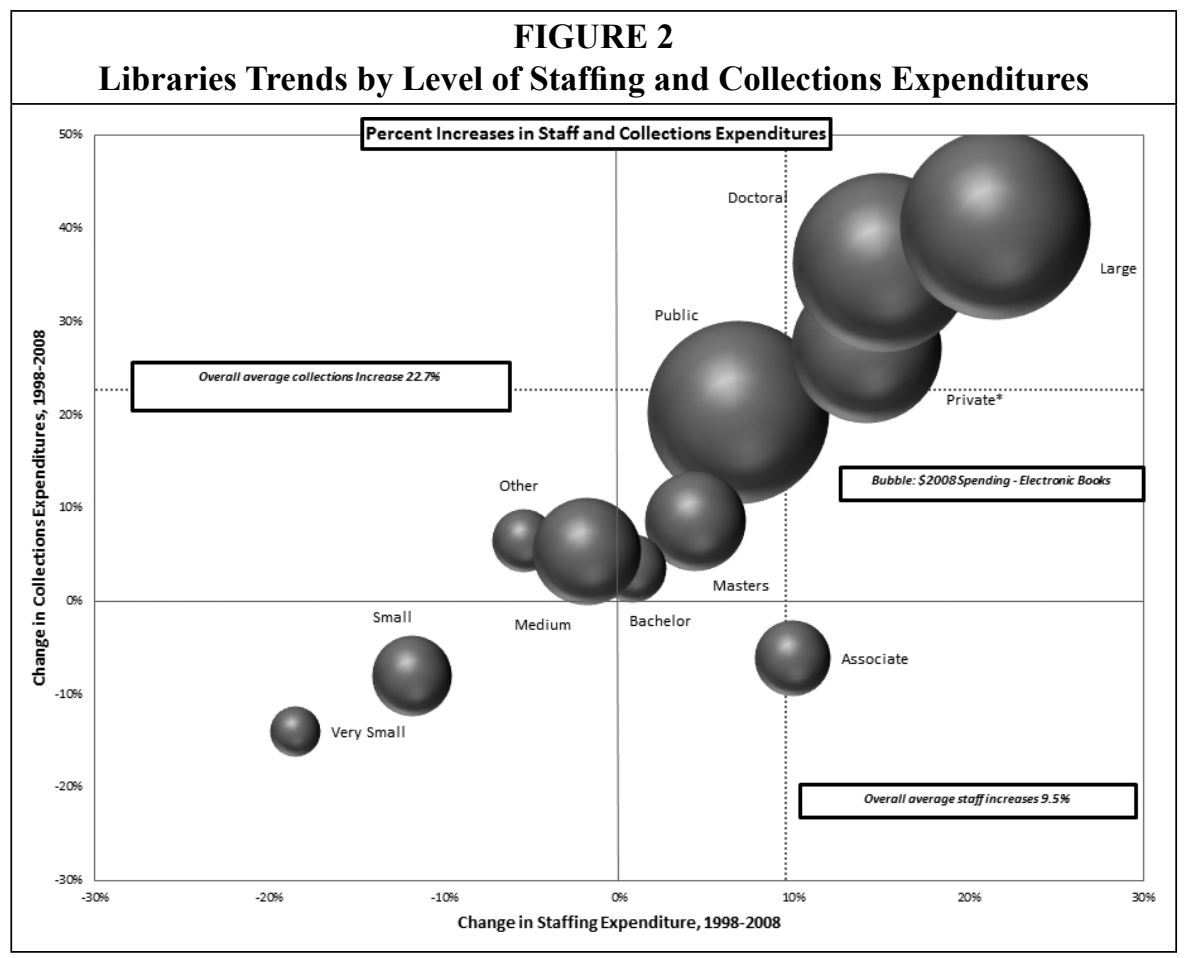




\begin{tabular}{|c|c|c|c|c|c|c|c|c|c|c|c|c|c|c|c|c|c|c|c|c|}
\hline & 㝕 & $\stackrel{t}{8}$ & กี & & 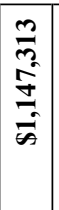 & 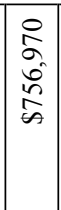 & $\mid \begin{array}{c}n \\
\infty \\
\infty \\
\infty \\
+\infty \\
\infty\end{array}$ & 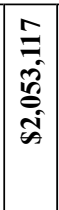 & & $\begin{array}{l}\vec{\infty} \\
\vec{n} \\
\vec{n}\end{array}$ & $\begin{array}{l}0 \\
0 \\
2 \\
2 \\
\tilde{n} \\
\tilde{n}\end{array}$ & $\begin{array}{l}\tilde{2} \\
\infty \\
\hat{\alpha} \\
\hat{\sigma}\end{array}$ & $\frac{\tilde{T}}{\tilde{\sigma}}$ &  & 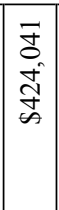 & $\begin{array}{l}\frac{a}{\infty} \\
\infty \\
\overrightarrow{2} \\
\infty \\
\infty\end{array}$ & $\begin{array}{l}\hat{\sigma} \\
\hat{\sigma} \\
\hat{\tilde{H}}\end{array}$ & $\begin{array}{l}0 \\
\infty \\
\infty \\
\infty \\
\infty \\
\infty \\
\infty\end{array}$ & $\begin{array}{l}0 \\
0 \\
+ \\
0 \\
0 \\
0\end{array}$ & 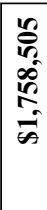 \\
\hline & $\stackrel{\infty}{2}$ & $\Theta$ & $\overline{\text { m }}$ & & \begin{tabular}{|c|}
$\hat{i}$ \\
$\infty$ \\
$\tilde{N}$ \\
$\tilde{N}$ \\
$\infty$ \\
$\infty$
\end{tabular} &  &  & 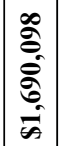 & & $\begin{array}{l}n \\
n \\
\tilde{o} \\
\delta \\
+ \\
\infty\end{array}$ & \begin{tabular}{l|}
$n$ \\
$\hat{n}$ \\
$\hat{\delta}$ \\
$n$ \\
$n$
\end{tabular} & $\begin{array}{l}\stackrel{m}{=} \\
\frac{\infty}{\infty} \\
\infty\end{array}$ & \begin{tabular}{l|}
9 \\
$\infty$ \\
$\infty$ \\
$\dot{f}$ \\
$\dot{\infty}$
\end{tabular} & \begin{tabular}{|l|} 
\\
$\vdots$ \\
$\tilde{b}$ \\
$\hat{n}$ \\
$\tilde{n}$
\end{tabular} & \begin{tabular}{l}
\multirow{+}{\sim}{} \\
2 \\
2 \\
$\delta$ \\
0
\end{tabular} & $\begin{array}{l}\infty \\
\stackrel{n}{\infty} \\
\infty \\
\infty \\
\infty\end{array}$ & 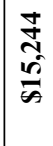 & $\begin{array}{l}n \\
n \\
n \\
0 \\
n \\
n\end{array}$ & \begin{tabular}{l} 
से \\
m \\
\multirow{n}{n}{} \\
$\tilde{n}$
\end{tabular} & 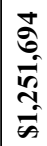 \\
\hline 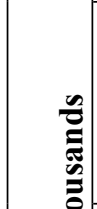 & 咅 & के & f & &  & 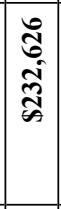 & \begin{tabular}{|l|}
$n$ \\
$n$ \\
$n$ \\
$\tilde{y}$ \\
$\infty$ \\
\end{tabular} & \begin{tabular}{l}
\multirow{2}{*}{} \\
\multirow{2}{\pm}{} \\
\multirow{2}{*}{} \\
\end{tabular} & & \begin{tabular}{|l|} 
\\
$\infty$ \\
$n$ \\
2 \\
$n$ \\
$n$ \\
$n$
\end{tabular} & \begin{tabular}{l|}
$\infty$ \\
$\tilde{\sigma}$ \\
$\tilde{\sigma}$ \\
$\bar{\sigma}$
\end{tabular} & 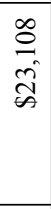 & 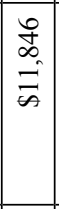 & $\begin{array}{l}\overrightarrow{\vec{\sigma}} \\
\vec{n} \\
\tilde{n} \\
\tilde{n}\end{array}$ & 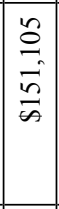 & $\begin{array}{l}0 \\
2 \\
2 \\
2 \\
\frac{1}{\infty}\end{array}$ & $\begin{array}{l}8 \\
0 \\
\infty\end{array}$ & 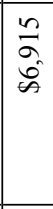 & 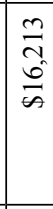 & $\begin{array}{l}n \\
0 \\
+ \\
0 \\
n \\
n \\
n\end{array}$ \\
\hline $\begin{array}{l}\bar{E} \\
\bar{E} \\
\tilde{\sigma} \\
\frac{\tilde{\sigma}}{v}\end{array}$ & $\stackrel{\infty}{\sigma}$ & ले & $\widetilde{\infty}$ & & $\begin{array}{c}\mathscr{8} \\
\stackrel{8}{\circ} \\
\stackrel{8}{8} \\
\dot{+}\end{array}$ & 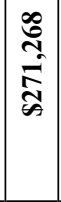 & 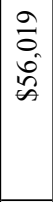 & 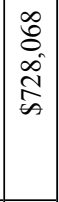 & & 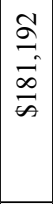 & 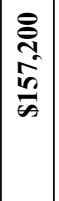 & $\mid \begin{array}{l}\hat{\delta} \\
\infty \\
0 \\
\hat{\theta} \\
\mid\end{array}$ & $\left|\begin{array}{l}\infty \\
\infty \\
\infty \\
\infty\end{array}\right|$ & 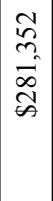 & $\begin{array}{l}\tilde{N} \\
m \\
\tilde{n} \\
\tilde{n} \\
\tilde{n}\end{array}$ & 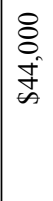 & $\begin{array}{l}\hat{R} \\
\hat{f} \\
\dot{f}\end{array}$ & $\begin{array}{l}2 \\
0 \\
0 \\
0 \\
\infty \\
\infty\end{array}$ & $\begin{array}{l}\tilde{n} \\
\tilde{n} \\
\delta^{2}\end{array}$ & $\begin{array}{l}n \\
0 \\
n \\
\infty \\
\infty \\
+ \\
\infty\end{array}$ \\
\hline 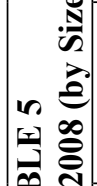 & 总 & बे & ঞ & & 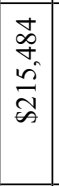 & 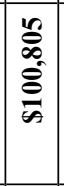 & $\mid \begin{array}{l}\vec{D} \\
\infty \\
\vec{n} \\
\tilde{\infty}\end{array}$ & $\mid \begin{array}{c}\vec{n} \\
\infty \\
\infty \\
5 \\
\infty\end{array}$ & & \begin{tabular}{|l|}
$n$ \\
$n$ \\
2 \\
$\infty$ \\
$\infty$ \\
$n$
\end{tabular} & 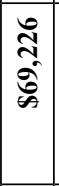 &  & \begin{tabular}{|l|}
$\hat{\alpha}$ \\
$\dot{a}$ \\
$\hat{n}$
\end{tabular} & 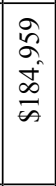 & $\begin{array}{l}0 \\
0 \\
0 \\
8 \\
2 \\
\infty\end{array}$ & 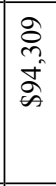 & $\stackrel{\hat{n}}{\tilde{n}}$ & 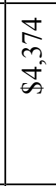 & $\begin{array}{l}\vec{J} \\
\dot{g}\end{array}$ & $\begin{array}{l}\infty \\
0 \\
2 \\
\alpha \\
\infty \\
\tilde{n} \\
\tilde{n}\end{array}$ \\
\hline 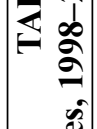 & $\stackrel{\circ}{2}$ & 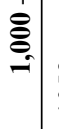 & $\tilde{\kappa}$ & & \begin{tabular}{|l|}
$\tilde{z}$ \\
$\hat{\sigma}$ \\
$\tilde{z}$ \\
$\tilde{n}$ \\
$\tilde{n}$
\end{tabular} & $\frac{\sigma}{a}$ & 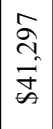 & 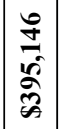 & & \begin{tabular}{|c|}
8 \\
$\delta$ \\
$\dot{d}$ \\
$\tilde{d}$ \\
$\dot{s}$
\end{tabular} & 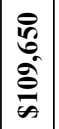 & $\begin{array}{l}n \\
\tilde{n} \\
n \\
n\end{array}$ & $\begin{array}{l}\dot{Z} \\
\stackrel{\sigma}{\sigma} \\
\hat{\sigma}\end{array}$ & $\begin{array}{c}\infty \\
0 \\
\infty \\
\infty \\
\bar{\infty} \\
\end{array}$ & $\begin{array}{c}m \\
\dot{d} \\
\dot{s} \\
\frac{n}{n}\end{array}$ & 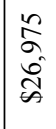 & $\begin{array}{l}0 \\
\infty \\
\infty \\
\tilde{n}\end{array}$ & $\begin{array}{l}\infty \\
0 \\
\infty \\
6 \\
\infty\end{array}$ & $\begin{array}{l}\tilde{\delta} \\
\tilde{\delta} \\
\tilde{n}\end{array}$ & $\begin{array}{l}\underset{\nabla}{\nabla} \\
\underset{\mathbb{a}}{n}\end{array}$ \\
\hline 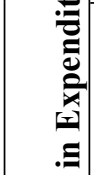 & $\stackrel{\infty}{\stackrel{\overbrace{}}{~}}$ & : & త్రి & & $\begin{array}{l}n \\
a \\
0 \\
0 \\
0 \\
\infty\end{array}$ & $\begin{array}{l}\mathscr{2} \\
\tilde{N} \\
\tilde{d}\end{array}$ & $\mid \begin{array}{l}\hat{\delta} \\
+ \\
2 \\
\hat{n}\end{array}$ &  & & \begin{tabular}{|c|}
0 \\
$m$ \\
$\tilde{n}$ \\
$\tilde{n}$ \\
$\tilde{n}$
\end{tabular} & \begin{tabular}{|l|}
$\infty$ \\
$\infty$ \\
$\infty$ \\
$\tilde{N}$ \\
$\infty$
\end{tabular} & $\begin{array}{l}\overrightarrow{\widehat{\sigma}} \\
\hat{\sigma} \\
\tilde{n}\end{array}$ & $\begin{array}{l}\tilde{N} \\
\tilde{n} \\
\tilde{N} \\
\tilde{s}\end{array}$ & $\begin{array}{l}\infty \\
\vdots \\
\infty \\
\infty \\
n \\
n\end{array}$ & 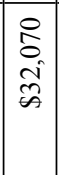 & 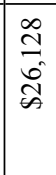 & $\begin{array}{l}\mathscr{\alpha} \\
\stackrel{\alpha}{\alpha}\end{array}$ & 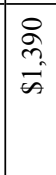 & $\begin{array}{l}\stackrel{ミ}{\Xi} \\
\dot{f}\end{array}$ & $\begin{array}{l}\hat{\sigma} \\
\hat{\sigma} \\
\hat{\sigma}\end{array}$ \\
\hline பี & $\stackrel{\infty}{\sigma}$ & 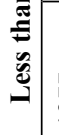 & 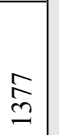 & & 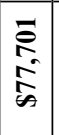 & $\begin{array}{l}\tilde{\hat{n}} \\
\tilde{n} \\
\tilde{n} \\
\tilde{n}\end{array}$ & \begin{tabular}{|c|}
$\infty$ \\
$\stackrel{\infty}{a}$ \\
$i$ \\
$\infty$ \\
$a$ \\
\end{tabular} & 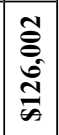 & & \begin{tabular}{|c|}
$\infty$ \\
0 \\
0 \\
$\tilde{f}$ \\
$\dot{f}$
\end{tabular} & \begin{tabular}{|c|}
$\hat{D}$ \\
$\infty$ \\
$\delta$ \\
$\dot{\theta}$ \\
$\dot{\infty}$
\end{tabular} & $\begin{array}{c}\hat{\infty} \\
\hat{N} \\
\tilde{N} \\
\tilde{\omega}\end{array}$ & $\begin{array}{l}\bar{b} \\
\hat{n} \\
\hat{n}\end{array}$ & $\begin{array}{l}8 \\
0 \\
0 \\
0 \\
0\end{array}$ & 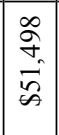 & 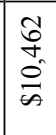 & $\frac{2}{i n}$ & 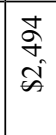 & $\begin{array}{l}\hat{\sigma} \\
\bar{\sigma}\end{array}$ & $\begin{array}{l}0 \\
0 \\
0 \\
0 \\
0\end{array}$ \\
\hline & $\sum_{\text {솝 }}$ & &  &  & 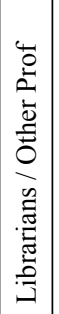 & 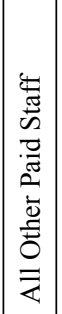 & 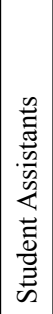 & 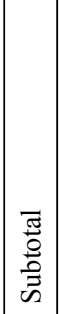 & 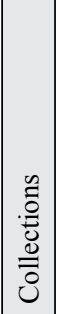 & $\begin{array}{l}\tilde{v} \\
\dot{0} \\
n\end{array}$ &  & 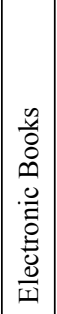 & 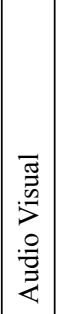 &  & 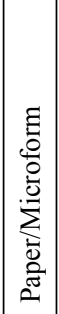 & 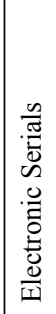 & 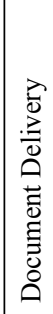 & 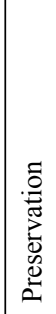 & 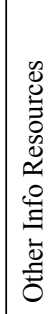 & $\begin{array}{l}\bar{\pi} \\
0 \\
0 \\
0 \\
\bar{n}\end{array}$ \\
\hline
\end{tabular}






institution; expenditures per institution, and expenditures per staff FTE per institution, which may be thought of as annual average wages per occupational category. Analyzing changes based on mean levels allows us to discern changes from 1998 to 2008, taking into account increases based on increases or decreases in the number of institutions participating in the study.

The trend in using other professional staff over the past decade is revealed most clearly when looking at differences according to Carnegie classification. Figure 3 presents these trends in visual form, looking specifically at the change in staffing by Carnegie classification between 1998 and 2008.

While FTEs per institution overall across all libraries was down by 8 percent over the period 1998-2008, all libraries increased their use of other professional staff by 44 percent. This was driven heavily by the use of other professional staff among doctoral research institutions. On a ratio basis, for every one staff FTE added as librarian staff to doctoral research institutions, 13 other professional FTEs were added. The increase in FTE/institution was from 10.1 to 16.2 among doctoral institutions; this compares to $0.3,0.2,0.2$, and 0.1 among masters', baccalaureate, associate, and all other institutions, respectively, over the same time period. Doctoral institutions also drive total spending on staff as over half $(53 \%)$ of all staff-related spending by all institutions in 2008 was by doctoral institutions.

In terms of institutional type (public, private/nonprofit, private/for-profit), staffing among public and private/ nonprofit has followed overall trends noted above generally. In the case of private/for-profit institutions, the use of all staff has increased considerably (again, most likely following the general increase of these institutions), but most rapidly (165\% and $164 \%$ respectively) for other professional and all other paid staff. 









Shifts in Library Utilization, 1998-2008

The following section provides an analysis of shifts in library utilization between 1998 and 2008. This is based on the creation of a metric that attempts to account for increases in enrollment and/or increases in the number of library hours. Otherwise, what might seem like increases in utilization (at an aggregate level) may in fact be simply due to increases in enrollment and/or hours.

This is achieved by calculating a ratio that is the product of the Gate Count (number of persons who physically enter library facilities in a typical week), Hours Open, and Enrollment. Not included in this analysis are those libraries in which their entire collection is electronic. ${ }^{17}$ Our measure therefore is Gate Count / Hours / Enrollment; this is then scaled by 1,000 to arrive at essentially a gate count per hour per 1,000 enrollments. Table 7 provides these estimates and results of significance testing by our selected Carnegie classes, institution type, and size class.
As can be seen in table 7, there has been decline in nearly all tracked metrics of library utilizations when normalized for student enrollment and available hours of the library. For example, the gate count of visitors in a typical week on an overall unadjusted basis has gone from 16.2 million in 1998 to 20.3 million in 2008; but when normalized by hours open and enrollment results in declines in all categories except baccalaureate, and small and mediumsized universities, and instead of a nearly 25 percent increase in gate count in the aggregate, there is a nearly 50 percent decline when normalized for hours open and student enrollment. Utilization of the general collection, the reserve collection, and reference transactions have declined in all classes of libraries regardless of type, size, and Carnegie category.

These trends may reflect the changing trends of the functional use of libraries from central depositories of circulating collections to shared meeting spaces. As the space allocated to paper-based 


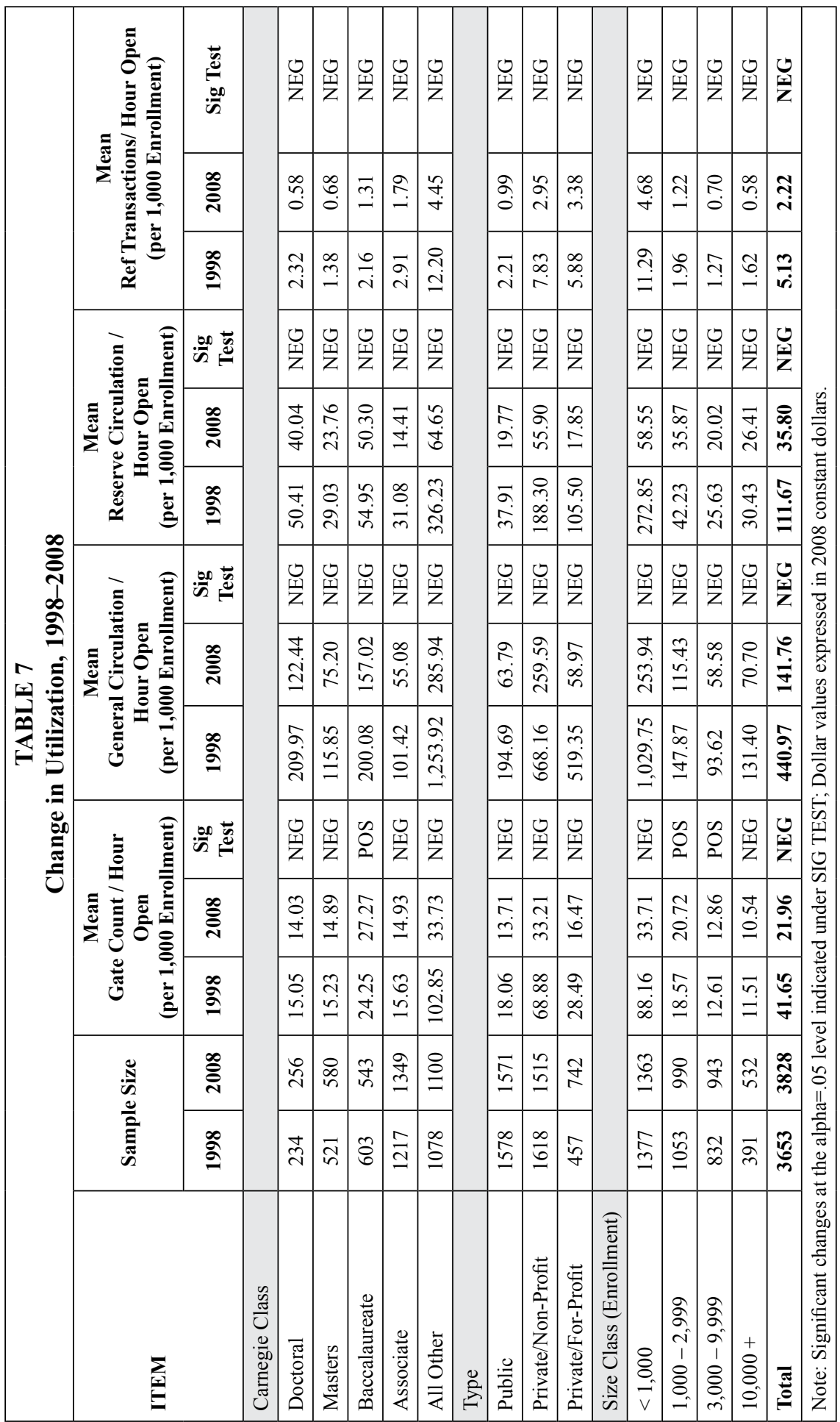


resources continues to contract, this space is being repurposed toward meeting space, collaboration, and, in some cases, the use of the library for academic support services. As the metrics in this study indicate, however, the utilization of the library even as new "collaboration space" is in decline in most institutions.

Figure 4 provides a visual indication of these trends-again, buoyed in large part by larger institutions and in particular those classified by doctoral research. Despite a nearly 7-fold increase in collection expenditures for large, doctoral, and public institutions, their utilization of the library has declined by $15 \%-20 \%$. Small to medium-sized baccalaureate and master's institutions, while making significant increased investments in their collections, have also seen a slight increase in library utilization over the period.

\section{Shifts in Cost per Unit, 1998-2008}

Table 8 takes available data and calculates per unit costs for 1) books, 2) e-books, 3) au- diovisual materials, and 4) all serials (both print and e-serial acquisitions) for the periods indicated. Physical materials (books and audiovisuals) remain largely the same over the period, while e-books and e-serials (with increased overall expenditures as indicated earlier) have shown dramatic decreases, of 72.7 percent for e-books and 87.1 percent for serials in per-unit costs. It appears that libraries are generating significant value in their e-materials investments, while their investments in physical collections have not been similarly improving, remaining flat, or increasing.

\section{Conclusions}

The study confirms a number of findings from previous studies and discussions regarding academic library trends, while also demonstrating some countervailing evidence regarding previously held notions about academic libraries.

Academic librarians and administrators as a group may indeed feel constrained by budget; but, over the study

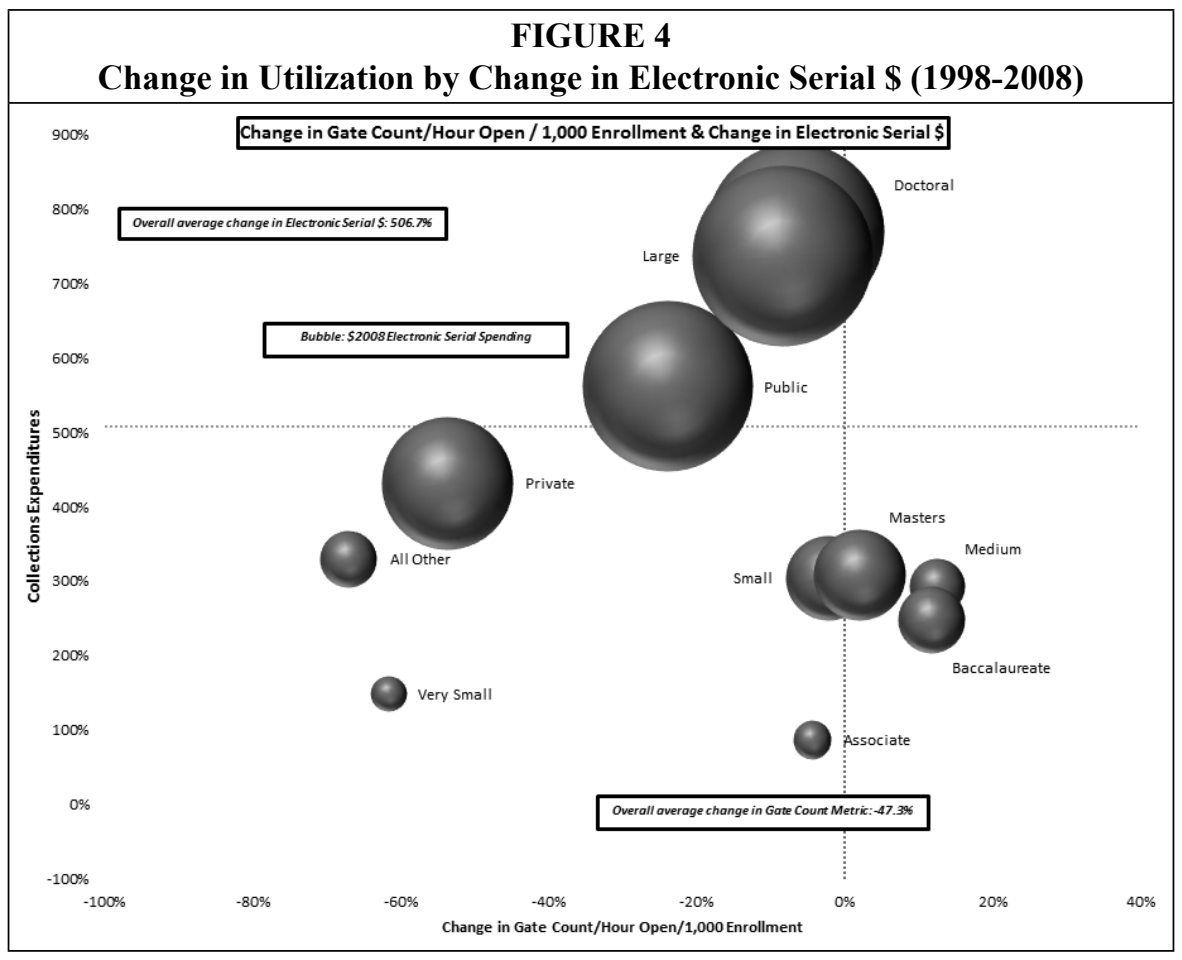




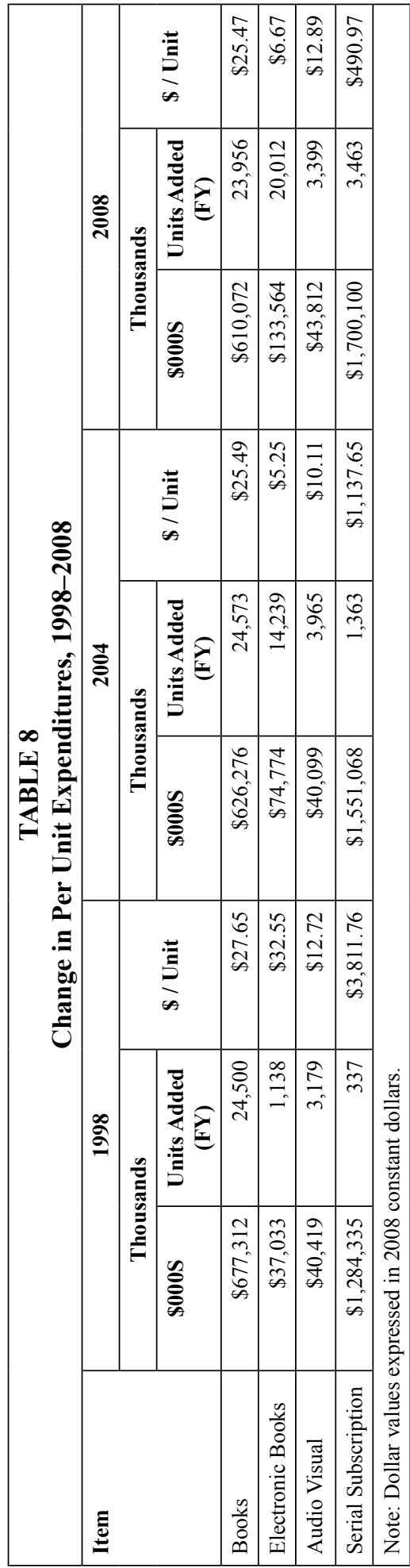

period, academic libraries have grown in real dollars by nearly 12 percent above inflation; their professional staffs have grown by nearly 15 percent, and funding for these staffs have increased by over 22 percent. In addition, their collections have been expanded by over 23 percent in current dollar funding, and serial and ebook collections have delivered dramatic value as indicated by reductions in perunit costs. In fact, few other educational institutions can point to such progress.

What also seems clear is that academic libraries cannot be treated as a homogenous group of institutions and that the drivers of the growth in this community come from the large, doctoral, private institutions; these libraries are far outpacing the growth of the group as a whole, particularly the investments that small, masters and baccalaureate, and public institutions can sustain.

Staffing is indeed diversifying, as suggested by earlier studies. Nonlibrarian professionals are the fastest-growing group of staff, with an increase of over 60 percent of other professionals added to doctoral institutions and 50 percent in private institutions during the period. Librarians as a group have remained constant, with no significant increases across all academic libraries, while other paid staff and library assistants have been reduced, presumably to fund in part the expansion of other professional staff.

With a very few exceptions, the use of the library physical (nonelectronic) assets are on a precipitous decline, when normalized for student enrollment and hours open. Visitors to the library measured by gate counts are down significantly in most categories of analysis, with private universities down by 50 percent; reference transactions have significantly declined in all categories of analysis and in doctoral universities are down 75 percent, and large institutions are down 64 percent in the period analyzed. Circulation of both general and reserve collections are also down in all categories of analysis, with a 68 percent and 62 percent decline in 


\section{U.S. Academic Library Shifts in Spending, Staffing, and Utilization 467}

general collection circulations at public and private institutions respectively, and a 71 percent decline in reserve circulations at private nonprofit institutions and an 83 percent decline at for-profit institutions. (The use of electronic materials was not part of this study, as such data is not yet available in the survey data used.)

It does seem clear that libraries are operating in two distinct environments where they make major investments in electronic services and new staff skills to support those services, while also trying to operate the physical library and its print collections. It is hard to imagine that this bifurcation of resources and programs is sustainable over a long period of time. It may well be that managing both the print collections with the requisite staff, while also investing in the electronic future and the skills needed to drive these new initiatives, is what is beginning to strain library resources.

Finally, it is clear from the data available that libraries are generating strong returns in their investments in electronic resources - in particular, e-books and e-serials, which are part of the digital libraries now available in the marketplace. Libraries and their institutions have benefitted from these electronic materials acquisitions as measured by reductions in per-unit costs. Though total acquisition costs of e-books and e-serials have increased by 261 percent and 507 percent respectively, as noted earlier a 79 percent decrease in e-book per-unit costs and an 87 percent decrease in per-unit serial subscriptions have been realized across all libraries in the period 1998-2008.

\section{Notes}

1. Carnegie classification system is developed by the Carnegie Foundation for the Advancement of Teaching and widely used in the study of higher education, both as a way to represent and control for institutional differences, and also in the design of research studies to ensure adequate representation of sampled institutions, students, or faculty.

2. K.L. Hahn, Research Library Publishing Services: New Options for University Publishing. Association of Research Libraries, Mar. 2008, available online at www.arl.org/bm doc/researchlibrary-publishing-services.pdf [accessed 29 August 2011].

3. "Academic Library Woes," American Library Association News, May 2009, available online at www.ala.org/ala/alonline/currentnews/newsarchive/2009/may2009/academiclibrarywoes051309. cfm [accessed 29 August 2011]; L. Blumenstein, "Around Academic Libraries, New Cuts and Charges: Washington U. Closes Two Libraries; Others Cut, Save Subscriptions," Library Journal, Sept. 17, 2009, available online at www.libraryjournal.com/lj/communityfunding/855778-268/story. csp [accessed 29 August 2011]; M. Kelley, “University of Washington iSchool, University Libraries Face Budget Pressures," Library Journal, Mar. 7, 2011, available online from www.libraryjournal. com/lj/communityacademiclibraries/889587-419/university_of_washington_ischool_university. html.csp [accessed 29 August 2011].

4. M.G. Brooks, "Organizational Leadership in Academic Libraries: Identifying Culture Types and Leadership Roles" (doctoral dissertation, Marshall University, 2007), available online at www.marshall.edu/etd/doctors/brooks-monica-2007-phd.pdf [accessed 29 August 2011].

5. ACRL Research Planning and Review Committee, "2010 Top Ten Trends in Academic Libraries: A Review of the Current Literature," College and Research Libraries News 71, no. 6 (2010): 286-92, available online at http://crln.acrl.org/content/71/6/286.full [accessed 29 August 2011].

6. Ibid.

7. Donna Dosrochers, et al., Trends in College Spending 1998-2008: A Report of the Delta Cost Project (Lumina Foundation, 2010), Indianapolis, IN.

8. Institute of Museum and Library Services, "Technology: Status of Technology and Digitization in the Nation's Museums and Libraries" (2001), available online at www.imls.gov/resources/ TechDig05/Technology\%2BDigitization.pdf [accessed 29 August 2011]. 373-76.

9. K. Coyle, "Libraries and Standards," Journal of Academic Librarianship 31, no. 4 (2005):

10. ACRL Research Planning and Review Committee, “2010 Top Ten Trends in Academic Libraries."

11. Christopher Stewart, "Half Full or Half Empty? Staffing Trends in Academic Libraries at U.S. Research Universities, 2000-2008," Journal of Academic Librarianship 36, no. 5 (2010): 394-400. 
12. Association of College and Research Libraries (ACRL), Value, Outcomes and Return of Investment of Academic Libraries (Chicago: ACRL, 2010).

13. S. Foo, A.S. Chaudhry, S.M. Majid, and E. Logan, Proceedings. World Library Summit, Keynote address: Academic Library Seminar, National Library Board, Singapore, April 22-26, 2002, available online at http://www3.ntu.edu.sg/home/assfoo/publications/2002/02wls_fmt.pdf [accessed 29 August 2011].

14. For more information regarding imputation methodology, see http://nces.ed.gov/ pubs2010/2010348.pdf (page 22 under Editing and Imputation).

15. Confidence interval calculations are generally based on an approximation of the t distribution. The distribution around our evaluated statistic provides the upper and lower bounds as described above. The $t$ distribution is generally used in most statistical applications when calculating confidence intervals and approaches a normal distribution as sample size increases. The t-test (upon which the distribution is based) is used for comparisons between only two groups. As noted, throughout this report, the comparisons are based on significant differences across different groups (in many cases more than two) for individual items (such as expenditures on books, staff, or utilization metrics).

16. Integrated Post-Secondary Education Data System.

17. This question was not asked in 1998; in 2008, 10 institutions responded that their collection was entirely electronic. Primary among the 10 is University of Phoenix, the well-known online institution; the largest in terms of enrollment is Walden University, based in Minnesota.
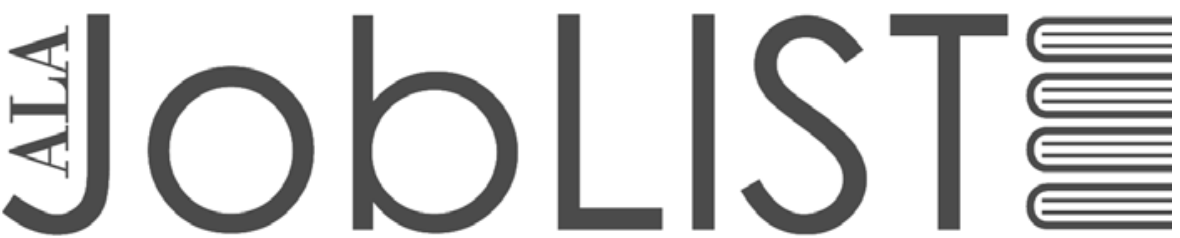

The \#1 source for jobs in Library and Information Science and Technology

\section{WHERE JOB SEEKERS AND EMPLOYERS GET RESULTS}

\section{JOB SEEKERS}

Search and sort hundreds

of job ads by position type,

employer, location, and more

\section{EMPLOYERS}

Strengthen your candidate pool-

ALA reaches the most engaged

professionals and students



\section{joblist.ala.org}

